\title{
A insuficiência lógica nas três imagens de Kenneth Waltz: uma crítica através do silogismo hegeliano
}

\author{
The logical insufficiency into Kenneth Waltz's three images: a critic \\ through hegelian syllogism
}

João Henrique Salles Jung ${ }^{1}$

\section{Resumo}

O objetivo deste trabalho é analisar as Relações Internacionais a partir do silogismo hegeliano no que tange a interação entre indivíduos, Estados e Sistema Internacional, elementos também conhecidos como "as três imagens de Waltz". Desta forma pretende-se demonstrar a insuficiência lógica presente na construção de Waltz, encaminhando uma crítica aos fundamentos do realismo estrutural.

Palavras-Chave: Teoria das Relações Internacionais. Realismo Estrutural. Silogismo. Lógica. Hegel

\section{Abstract}

The aim of this paper is to analyze International Relations through hegelian syllogism. The main focus embraces interaction among individuals, States and international system, in which is knew as the Waltz's third images. Thus is aimed to expose the logical lack into Kenneth Waltz theory, which brings critics to the fundamentals of neorealism/structural realism.

Keywords: International Relations Theory. Structural Realism. Syllogism. Logics. Hegel.

\section{Introdução}

O objetivo deste trabalho é, através da aplicação do silogismo hegeliano, demonstrar que a lógica das três imagens de Waltz estão equivocadas. Tal prova coincide com uma crítica mais ampla ao neorrealismo, também compreendido como o realismo estrutural que se popularizou a partir de Kenneth Waltz e das obras "Theory of International Politics" e "The Man, the State, the War". Para tal empreendimento é feita a leitura das Relações Internacionais enquanto conceito, conforme empregado por Hegel (2018), para interpretar as três imagens propostas por Waltz enquanto silogismo.

\footnotetext{
${ }^{1}$ Mestrando em Filosofia - PUCRS. E-mail: joaojunj@outlook.com
} 
Em conjunto, serão utilizados alguns autores conhecidos por estabelecer críticas ao projeto neorrealista, como Colin Elman (1996), Alexander Wendt (1995), Richard Ashley (2000), Buzan e Little (2000), cada um destes pegando determinados pontos do quadro-geral do neorrealismo a fim de mostrar a insuficiência teórica do programa de Waltz. Pretende-se, então, adentrar dentro deste rol de críticos, embasando-se nestes e na lógica hegeliana a fim de apontar o problema lógico intrínseco ao neorrealismo.

Apesar da crítica contundente, a ideia deste artigo não é desmerecer o trabalho de Waltz (1979; 2001), até por este demonstrar grande erudição para conceber sua obra. Dialogando com uma vasta tradição da filosofia política, Waltz utiliza-se principalmente de uma vertente rousseauniana para defender a tese central de sua obra, a de que é na terceira imagem, a do sistema, que estão as causas dos conflitos visualizados na política entre as nações (WALTZ, 2001, p. x).

Ao neorrealismo é cara a noção de sistema, pois é a partir daí que o próprio prefixo "neo", que os separam dos realistas clássicos, é criado. No fetiche pelas análises sistêmicas acabam por incorrer a problemas lógicos, ao considerar o sistema como um ser-em-si, um elemento em si mesmo. Tal descompasso com uma leitura diacrônica da política internacional leva à "pobreza do neorrealismo" citada por Ashley (2000) e Elman (1996) e à incapacidade da teoria compreender as mutações que ocorrem na esfera internacional.

Logo, o problema que inspira este trabalho é questionar: em que medida o silogismo hegeliano pode demonstrar a insuficiência lógica das três imagens de Kenneth Waltz sobre as Relações Internacionais? Acredita-se que com o uso da lógica hegeliana, centralmente na instrumentalização do silogismo da necessidade, consegue-se demonstrar como o neorrealismo é logicamente inadequado.

Essa é a justificativa que dá fôlego a este estudo, tendo em vista que a lógica raramente é visualizada em estudos que concernem às relações internacionais, sendo, inclusive, pouco utilizada na análise teórica desta matéria. Ainda, deve-se lembrar que tal aproximação, neste caso, é coerente ao se ter em vista que tanto o silogismo quanto o neorrealismo se encaixam em perspectivas que pressupõem um sistema.

Para realizar tal empreendimento, inicialmente se resgatará a construção das três imagens em Waltz e os respectivos pilares do neorrealismo enquanto teoria das 
Relações Internacionais. Após, em uma segunda seção, montar-se-á tais imagens num esquema lógico a fim de demonstrar como já no nível lógico Waltz recai em erros que comprometem o desenvolvimento teórico do neorrealismo.

\section{Encontrando problemas: as três imagens de Kenneth Waltz}

Buscando explicar a forma com a qual guerras eclodem, Kenneth Waltz lança como tese de doutoramento aquilo que se tornaria posteriormente uma das principais obras das Relações Internacionais: o Homem, o Estado e a Guerra (WALTZ, 2001). Como o próprio título da obra indica, o autor tenta explicar o fenômeno dos conflitos internacionais através de três níveis de análise: o nível do indivíduo (que com influência hobbesiana era já utilizada pelo realismo clássico para explicar a guerra); o nível do Estado (até então a principal esfera de análise para se conceber as relações internacionais); e a sua grande contribuição, o nível do sistema.

O autor chama de imagem cada um dos níveis separando, assim, o conceito das Relações Internacionais em três imagens: i) o indivíduo; ii) o Estado-nação; iii) o sistema internacional. A definição de imagem vem a partir do pressuposto do autor de que "ver" a política internacional é impossível, por isso seria necessário criar imagens que pudesse criar sub-níveis de análise para, assim, poder se compreender as relações internacionais. Sua contribuição confunde-se com a própria influência do neorrealismo nas Relações Internacionais ao se ter em vista que Waltz, além do percursos de tal corrente, é ainda o mais influente intelectual da mesma.

A obra (WALTZ, 2001) se desdobra fazendo análises sobre a origem da guerra em cada uma das imagens para, no final, defender que é no nível do sistema que esta pode ser bem compreendida. Assim, contrasta-se com outras correntes teóricas que colocam na natureza humana ou na forma de organização estatal os motivos para os conflitos. Os realistas clássicos, como Morgenthau (2003), são bons exemplos daqueles que dão ênfase ao indivíduo; enquanto no liberalismo, em vertentes como na teoria da paz democrática de Michael Doyle (2012), percebe-se a maior preocupação com as formas de organização estatal. 
Waltz parte do pressuposto de que o Estado é um ator unitário (2001; 1979), composto por vontade e propósito, o que o coloca enquanto agente universal. Tal constructo serve para elevar à terceira imagem o foco de análise da guerra; é aqui que Waltz (2004) traz sua inovação ao colocar no caráter anárquico do sistema internacional o porquê de guerras ocorrerem. Não havendo uma instituição superior aos Estados, estes se regulam através do outro; é aqui que já percebemos um problema lógico.

Na concepção apresentada por Waltz (2001), o Estado seria um ser-posto mediado através das relações travadas no seio do sistema internacional. Mas como poderia o Estado constituir um ser-posto se o mesmo é ontologicamente precedente ao próprio sistema? A construção da terceira imagem de Waltz (2004) leva a noção de que a estrutura, o sistema internacional, seria um ser-em-si-e-para-si. Mas como poderia o sistema configurar tal caracterização do conceito se o próprio é construído historicamente através de uma série de interações?

O trabalho de Adam Watson (2004) surge como um importante aliado ao demonstrar como a estrutura internacional muda de tempos em tempos, sendo um sincronismo teórico falar sobre um sistema internacional ontologicamente anárquico. Através da recuperação que Watson (2004) faz da história da política internacional, pode-se compreender o que Alexander Wendt (1995) diz ao afirmar que "a anarquia é o que os Estados fazem". Este trabalho de matriz epistemológica construtivista tem a intenção de desmontar exatamente o pressuposto de que o sistema internacional é ontologicamente anárquico.

O trabalho Buzan e Little (2000) é aqui, enfim, duplamente útil ao argumentar tanto que ao neorrealismo falta um senso de história que se encaixe na teoria de Waltz quanto pela própria crítica à noção de Sistema Internacional, central à corrente e que engloba o que é colocado por Waltz (2001) enquanto a terceira imagem. Faltam definições substanciais, embasadas historicamente, para que se possa afirmar a existência de um sistema internacional (BUZAN; LITTLE, 2000, p.1274); se é que ele existe.

Com a ideia de pêndulo presente em Watson (2004), percebe-se ao longo dos século organizações políticas supranacionais que migram de organizações imperiais à isoladas, cabendo entre estes dois extremos diversas formas de organização sistêmicas e sub-sistêmicas. Nesse escopo retoma-se a crítica feita por Ashley 
(2000) sobre a pobreza do neorrealismo de Waltz. Em Richard Ashley (2000) encontra-se um interlocutor para dirigir críticas a tal corrente de pensamento, ao denunciar inicialmente o estruturalismo a-histórico althusseriano que influencia a obra Waltz. A expressão “probreza do neorrealismo” é também encontrada na obra de Colin Elman (1996a), o qual se correspondeu com o próprio Kenneth Waltz através de artigos críticos nos quais um tentava refutar o outro².

A principal contribuição crítica de Elman (1996a) é o argumento de que a teoria neorrealista não é apta para política externa tendo em vista quatro questões: i) que a lógica interna do argumento neorrealista falha em produzir predições pois ii) a influência do nível de unidade no neorrealismo [a análise sistêmica] irá interferir na acuidade de qualquer predição, pendendo a encontrar causas e consequências sistêmicas, agravado pelo fato de iii) o modelo neorrealista ser baseado em mecanismos de seleção evolutiva; e, por fim, iv) que as variáveis teóricas neorrealistas são pobremente conceitualizadas e operacionalizadas.

Ao se ter como referências alguns poucos autores das Relações Internacionais, percebe-se que há uma série de possibilidades em se criticar a obra de Kenneth Waltz $(1976 ;$ 2001) e o próprio edifício do neorrealismo. O sistema de Waltz é uma tentativa de racionalização das Relações Internacionais, através de uma perspectiva que essencializa e estanca o nível de análise desta matéria. Nesse sentido, os pós-estruturalistas e as correntes teóricas advindas do debate interparadigmático irão contestar as reivindicações teóricas neorrealistas. Ao mesmo tempo, dentro do próprio esquema podem ser apontados equívocos lógicos que comprometem o sistema sem nem ser necessária a crítica da existência de um sistema em si.

A partir de então, o sistema montado por Waltz (2001) será analisado através da perspectiva do silogismo hegeliano, a fim de se compreender a articulação entre indivíduo, Estado e sistema internacional a partir das determinações do conceito Relações Internacionais. Logo, a ideia é analisar a estrutura lógica do argumento de Kenneth Waltz para assim, então, demonstrar a insuficiência lógica do seu modelo; sugerir-se-á, assim, um novo molde para se compreender as Relações Internacionais através do silogismo hegeliano.

\footnotetext{
2 Para mais informações, veja o artigo "Cause, Effect, and Consistency: a response to Kenneth Waltz" (1996b) no qual Colin Elman faz uma tréplica a Waltz.
} 


\section{6 | Opinião Filosófica, V. 11, Dossiê - Teoria do Objeto na Lógica de Hegel}

\section{O silogismo hegeliano e a mostra de insuficiência lógica no sistema neorrealista}

A mediação entre Hegel e as Relações Internacionais não é algo tão usual; o próprio filósofo não se dedicou especificamente a este tema, ainda que suas obras que se referem à Filosofia da História e à Filosofia do Direito sejam constantemente utilizadas por filósofos e cientistas políticos no debate entre comunitarismo e liberalismo. Ainda assim, não necessariamente sobre Relações Internacionais. Contudo, a possibilidade em realizar tal mediação entre Hegel e tal campo de estudos pode ser absorvida através das obras de Adriaan Peperzak (1994) e Agemir Bavaresco (2001).

Enquanto Peperzak (1994) mescla elementos da Filosofia do Direito (HEGEL, 2005) e do Espírito Objetivo ${ }^{3}$ para resgatar princípios hegelianos e constituir uma leitura do direito internacional a partir de Hegel; Bavaresco (2001) se utiliza da Filosofia do Direito (HEGEL, 2005) para constituir um conceito sólido de soberania e assim problematizar a dicotomia entre soberania interna e soberania externa. Após, é utilizada a ciência da lógica (HEGEL, 2018) no intuito de se valer do silogismo enquanto forma de mediar a relações entre os dois tipos de soberania. Percebe-se, portanto, que do Espírito à Lógica é possível resgatar princípios hegelianos no intuito de construir uma análise das Relações Internacionais. Como já aludido neste texto, dar-se-á maior ênfase à lógica em Hegel, mais especificamente, ao silogismo.

O silogismo em Hegel é a forma com a qual é possível compreender um determinado conceito (IBER, 2012). No terceiro volume da ciência da lógica, Hegel (2018) dedica sua atenção à doutrina do conceito, o que neste trabalho é colocado enquanto as Relações Internacionais. Se tal campo de estudo é encarado enquanto conceito, é necessário tratar seu interior através de algum silogismo para que se possa fundamentar e compreender tal campo.

Tal constructo intelectual diferencia-se do que até então tinha-se na filosofia, sendo esta estrutura lógica conhecida centralmente a partir de Aristóteles (ORSINI, 2018). Mas em Aristóteles era vislumbrado um outro esquema lógico para tratar do silogismo, consistindo então em uma terminus minor (premissa menor), uma

3 Corresponde à segunda seção da Filosofia do Espírito presente na Enciclopédia das Ciências Filosóficas (1995). 
terminus maior (premissa maior) e uma terminus medius (premissa média) (IBER, 2012). Para Iber (2012, p.11), o problema em Aristóteles, que levará ao grande rearranjo em Hegel, é que a conclusão contém a predicação inferida; o termo médio desaparece.

Através das determinações do conceito (singularidade, particularidade e universalidade) é que Hegel (2018) concebe seu esquema lógico, organizando-o e regendo- de modo dialético-especulativo (ORSINI, 2018). É por isso que em Hegel, ao contrário do que encontramos em outras propostas de silogismo, o termo médio será fundamental pois é nele que se encontrara a mediação para a produção de uma síntese do próprio silogismo. Assim, primeiro colocar-se-á a obra de Waltz (2001) dentro da estrutura do silogismo para então apontar como há um confusão nos seus fundamentos lógicos.

Conforme Christian Iber (2012, p.6): “A universalidade do conceito é, antes pelo contrário, o princípio que rege as especificação da coisa, que, portanto, resultam dela”. Como evidenciado anteriormente, para Waltz (2001; 1979) o sistema internacional constitui a determinação universal por ser a expressão do serem-si-e-para-si. Tal questão se evidencia centralmente nos capítulos 3,5 e 7 da obra de Waltz (2001), quando ao falar sobre as implicações das três imagens, o autor coloca o indivíduo e o Estado relacionados com efeitos pontuais, enquanto apenas no nível sistêmico podem ser percebidas consequências estruturais universalizantes - o que ele traz aos exemplos da economia, política e história. Tendo tal ponto em vista, como pode-se pensar as outras duas imagens no sentido das determinações do conceito?

No capítulo 3, ao dissertar sobre os impactos da primeira imagem, Waltz (2001) deixa claro sua visão de que o comportamento do indivíduo não pode ser encarado como ser-em-si, mas sim, como condicionado através de fatos sistêmicos. Tal asserção fica evidente quando o autor traz o seguinte caso (WALTZ, 2001, p. 58):

The Maoris and the Japanese were both suddenly subject to the impact of a powerful civilization almost entirely new to them. Under the impact they changed many of their past customs - and kept many others. In the case of the Maoris and the Japanese, physical force supplemented the force constituted by cultural impact. 4

4 Os Maoris e os Japoneses foram ambos repentinamente sujeitos aos impactos de uma poderosa civilização quase inteiramente nova a eles. Sob tal impacto eles mudaram uma série de costumes 


\section{8 | Opinião Filosófica, V. 11, Dossiê - Teoria do Objeto na Lógica de Hegel}

Tal trecho vem em meio a um debate travado entre o autor, psicólogos e cientistas behavioristas a respeito das causas da guerra, na qual o primeiro argumenta que (WALTZ, 2001, p. 59): "if the behavioral scientist can tell us what should be done to remove these causes, we still have a good bit more than half the battle to fight”. 5 Ou seja, não adianta pensar em outros comportamentos do indivíduo enquanto forma de evitar o conflito; tal cenário não se alteraria em nada.

O grande ponto defendido por Waltz $(2001 ; 1979)$ é o argumento de que se confunde causa com consequência e que o comportamento do indivíduo, assim como demonstrada na supracitada citação direta, é causa de consequência políticas ocorridas no nível sistêmico. A própria identificação do sujeito através da cultura seria uma determinação sistêmica.

No nível do Estado, a segunda imagem, a mesma estrutura argumentativa é utilizada por Waltz (2001). Ao citar as Leis de Platão e as forças revolucionárias francesas em contraposição à Política de Aristóteles, Waltz (2001, p. 124) constitui sua noção de Estado; na realidade, a construção de um Estado que ele quer colocar enquanto subjugado ao sistema internacional. Dirigindo críticas duras tanto a liberais quanto a marxistas - "Marx and the Marxists represent the fullest development of the second image"6 (WALTZ, 2001, p. 125) - o autor argumenta que democracia, capitalismo, socialismo, ou qualquer que seja a forma de organização estatal, não alterará o fato da iminência do conflito.

Através das instância "There is no shortage of instances in which the vision of liberals and of socialist revisionists has seemed true"7 (WALTZ, 2001, p.156) o autor deixa claro sua posição ao citar personagens que vão de Lênin (p. 137) a Nixon (p. 157). A soberania estatal sem um sistema de justiça que comprometa os Estados leva a julgamentos egoístas por parte desses, que baseados no auto-interesse criam conflitos (WALTZ, 1979; 2001). Como que se as imagens representassem um nível hierárquico, a segunda imagem possui algumas prerrogativas a mais quando

antigos - mantendo e absorvendo vários outros. No caso dos Maoris e dos Japoneses, a força física suplementou a força constituída através do impacto cultural. (tradução própria)

${ }_{5}$ Se o cientista behaviorista pode nos dizer o que deve ser feito para remover essas causas, nós continuaremos a ter ainda mais que a metade da batalha para lutar. (tradução própria).

${ }^{6}$ Marx e os Marxistas representam o mais completo desenvolvimento da segunda imagem. (tradução própria).

${ }_{7}$ Não há nem um breve instante no qual a visão dos liberais ou dos socialistas revisionistas tenha parecido verdade. (tradução própria) 
comparadas ao indivíduo, o que traz a reflexão de como se constituir as determinações do conceito a partir delas.

Através de Iber (2012) é possível compreender as formas como se articulam e se originam as determinações do conceito em Hegel (2018). As determinações não são distintas do universal, mas sim, especificações deste, formas peculiares em configurações particulares (IBER, 2012, p. 7). O universal só pode ser apreendido a partir de particulares que possam suprassumir este próprio universal (HEGEL, 2018), sendo a síntese do universal e do particular a singularidade.

Ao se ter em vista tal perspectiva, pode-se abarcar o singular enquanto o Estado, a segunda imagem. Isso porque a singularidade é a medida imanente da universalidade e da particularidade, é o ponto no qual ambas determinações são inseparáveis. O ponto de união entre sistema e indivíduos é o Estado, pois é através do Estado que o indivíduo é organizado politicamente, assim como é a partir desta entidade que o próprio sistema pode ter algo a regular. Nesse ponto, Kenneth Waltz (1979; 2001) mostra uma boa assumpção ao colocar o Estado como a segunda imagem, representando um elo de ligação. O problema então vem em seu prognóstico, na tese de que é no nível estrutural, no sistema internacional, que os conflitos podem ser explicados.

Tem-se então o sistema internacional enquanto o universal do esquema neorrealista, pois como supracitado, representa o ser-em-si-e-para-si. Com o Estado sendo a síntese lógica do universal com um determinado particular, representando assim o singular, o indivíduo se constitui enquanto particular. Contudo, como Waltz argumenta nos capítulos 6 e 7, seria o sistema que faria a mediação entre o Estado e o indivíduo, pois no nível sistêmico estão os condicionantes da imanência na primeira e na segunda imagem. Desta forma percebe-se que o silogismo das Relações Internacionais enquanto conceito segundo Waltz (1979; 2001) seria o representado pela figura S-U-P, no qual a universalidade atua como mediação entre singular e particular.

Com Orsini (2016) pode-se perceber que tal estrutura lógica representa a terceira figura do silogismo do ser-aí. A questão é que, através de tal silogismo, configura-se uma nova possibilidade, pois se o universal é o mediador, os próprios extremos tornam-se universais. Assim, o silogismo da terceira figura do ser-aí é essencialmente um universal (ORSINI, 2016, p. 44). Assim, a determinidade dos 
extremos não está contemplada no universal, mas sim, exterior a eles mesmos, o que leva a um cenário de igualdade entre as determinações do conceito e, respectivamente, à emergência do silogismo matemático representado pela figura U-U-U. Dentro deste silogismo, ainda que haja uma determinação mediadora, tal mediação não possui determinação alguma frente aos extremos.

Assim percebe-se que querer atribuir a cada uma das determinações, ou, como trabalhado aqui neste artigo, a cada uma das imagens, uma pretensa capacidade em determinar outra, recai numa falência da lógica. Logo, querer argumentar que é no nível do sistema internacional que devem ser explicadas as causas da guerra é tão errado quanto querer defender que o conflito é causado a partir da natureza humana ou da organização do Estado. Ao se ter isso em vista, pode-se supor que conflitos emergem a partir da articulação das três imagens, que não sistematicamente determinam umas outras mas sim, a partir das particularidades conjunturais tem relevâncias e papeis distintos em casos diferentes.

\section{Considerações finais}

Tal noção de estrutura e essencialização da política internacional é justamente um dos principais pontos criticados no neorrealismo (BUZAN; LITTLE, 2000) - e em teorias epistemologicamente positivistas - a partir do advento do debate interparadigmático e da emergência de novas possibilidades epistemológicas nas Relações Internacionais (LAPID, 1989). A pobreza do neorrealismo está, enfim, tanto nos pressupostos que balizam sua realização - positivismo, utilitarismo e sincronia - quanto na efetivação de suas análises.

Certamente outros métodos poderiam (e na verdade são) ser utilizados para criticar a obra de Kenneth Waltz e, respectivamente, o neorrealismo. Seja através de uma análise histórica, econômica, hipotética-dedutiva, ou qualquer outro método que seja, desmontar os fundamentos do neorrealismo é possível. Neste caso, optou-se pelo lógica, mais especificamente o silogismo hegeliano, enquanto método de se desconstruir as premissas trazidas por Waltz.

O fetiche por sistemas tira a capacidade de análises que deem conta de uma sociedade internacional em constante mutação (WATSON, 2004), que já superou o 
estatocentrismo e, respectivamente, a possibilidade de ser percebida através de ferramentas como teoria dos jogos. Além disso, há o próprio anacronismo de ser uma corrente criada pelo e para o contexto da Guerra Fria (ELMAN, 1996). Como já aludido neste trabalho, em Richard Ashley (2000) encontramos um expoente do pós-estruturalismo que critica o neorrealismo justamente pelos motivos supracitados. Se o fato de conceber um sistema para interpretar as relações internacionais já é problemático, constituir um sistema logicamente infundado é ainda pior.

Dentro do próprio universo lógico que Waltz propõe - ainda que possivelmente a lógica, ainda mais a hegeliana, não tenha sido uma preocupação para o autor - vislumbra-se a insuficiência em atribuir ao sistema internacional a prerrogativa de nível no qual pode ser explicado o conflito internacional. Com o silogismo matemático, derivado da terceira figura do silogismo do ser-aí, percebese que a determinação do conceito é triplamente universal, não cabendo o papel de determinador ao universal inicial ainda que sobre ela possa haver uma capacidade de mediação no silogismo. Ou seja, não pode-se conceder ao sistema internacional a prerrogativa de ser o nível que explica a origem dos conflitos e, respectivamente, nem que tal nível seja condicionante dos demais níveis/figuras.

Desta forma, homem, Estado e sistema - as três imagens de Waltz correspondem-se em grau de igualdade enquanto elementos que influenciam a ordem internacional. Ainda, poderiam ser pensados outros elementos para se acrescentar a esta equação enquanto variáveis que afetam as relações internacionais; contudo, isto já seria conteúdo para um outro trabalho.

\section{Referências}

ASHLEY, Richard. The poverty of neorealism. In: LINKLATER, Andrew. International Relations Critical Concepts. Volume IV. London/New York: Routledge, 2000.

BAVARESCO, Agemir. A crise do Estado-Nação e a teoria da soberania em Hegel. In Sociedade em Debate, v.7, n.3, 2001, pp.77-109.

BUZAN, Barry; LITTLE, Richard. The idea of "international system": theory meets history. In: LINKLATER, Andrew. International Relations: Critical Concepts. Volume IV. Routledge: London/New York, 2000. 
DOYLE, Michael. Liberal Peace: Selected Essays. Oxon: Routledge, 2012.

ELMAN, Colin. Horses for Courses: why not neorealist theories of Foreign Policy?. In Security Studies, v.6, n.1, pp.7-53, 1996.

PEPERZAK, Adriaan. Hegel contra Hegel in His Philosophy of Right: The Contradictions of International Politics. In Journal of the History of Philosophy, v.2, n.2, 1994, pp. 241-263.

HEGEL, Georg. W. F. Enciclopédia das Ciências Filosóficas - em compêndio (1830). Vol. III - A Filosofia do Espírito. São Paulo: Edições Loyola, 1995.

HEGEL, Georg W. F. Introdução à filosofia do direito. Campinas: UNICAMP, 2005.

HEGEL, Georg W. F. Ciência da lógica: 3. A doutrina do conceito. Petrópolis: Vozes, 2018.

IBER, Christian. Conceito, juízo e silogismo: Introdução à lógica do conceito. In Revista Opinião Filosófica, v.3, n.2, Porto Alegre, 2012.

LAPID, Yosef. The third Debate: On the Prospects of International Theory in a PostPositivist Era. In: International Studies Quarterly, vol.33, n.3, 235-254, 1989.

MORGENTHAU, Hans. Política entre as nações: a luta pelo poder e pela paz. Brasília: UnB, 2003.

ORSINI, Federico. A teoria hegeliana do silogismo: tradução e comentário. Porto Alegre: Editora Fi, 2016.

WALTZ, Kenneth. Theory of International Politics. Reading: Addison-Weasley, 1979.

WALTZ, Kenneth. Man, the State, and war: a theoretical analysis. New York: Columbia University Press, 2001.

WATSON, Adam. A evolução da Sociedade Internacional. Brasília: UnB, 2004.

WENDT, Alexander. Anarchy is What States Make of it: The Social Construction of Power Politics. In: DER DERIAN, James. International Theory: Critical Investigations. New York: New York University Press, 1995.

Recebido em: 26/12/2019.

Aprovado em: 17/03/2020. 